\title{
Case study of technological problems arising from the use of new material, DOMEX steel sheet, on the components of the mower discs on the example of the production company SaMASZ Sp. Z o. 0 .
}

\author{
Damian Kułak ${ }^{1, *}$, Jerzy Jaroszewicz ${ }^{2}$, Marcin Woronko ${ }^{3}$ \\ ${ }^{1}$ Enterprise SaMASZ Sp. Z o.o., 15-161 Białystok, ul. Grass 15, Poland \\ ${ }^{2}$ Bialystok Technical University, Department of Production Management, 16-001 Kleosin, ul. Father \\ Tarasiuk 2, Poland \\ ${ }^{3}$ Graduate of Bialystok Technical University, Department of Production Management, 16-001 \\ Kleosin, ul. Father Tarasiuk 2, Poland
}

\begin{abstract}
The paper describes the improvement of technological process of knife holder production used in disc mowers at SaMASZ Sp. With o.o. The improvement was aimed at eliminating cracks in the press of a $500 \mathrm{t}$ crank press press crush that occurred after the Boron 27 starting material was changed to Domex MC 500 high strength steel. The technology of regeneration of claws with identified operational cracks and a stand for fatigue tests was also proposed. Defectoscopy and strength testing methods have been developed to verify that the structure of the regenerated material is free from cracks or micro cracks in the material.
\end{abstract}

Keywords: knife holder, Boron 27, Domex, fatigue tests, defectoscopic examination

\section{Introduction}

The subject of the publication is the problem of cracking knife holders used in Perfect CUT disc mowers during pre-pressing. The problem was due to the substitution of the Boron 27 starting material on the DOMEX 500MC high strength sheet [1].

Changing the material without adjusting the stigma of the handler and cutting system on the sheet during laser cutting resulted in numerous defects in the form of cracks, micro cracks and corrugations [2].

\footnotetext{
*Corresponding author: damian.kulak@samasz.pl

Reviewers: Richard Pastričák, Františka Pešlová
} 


\section{The construction and technological characteristics of the knife holder}

The knife holder is one of the parts of the rotating disc, the cutting unit of the Perfect CUT cutter [3].

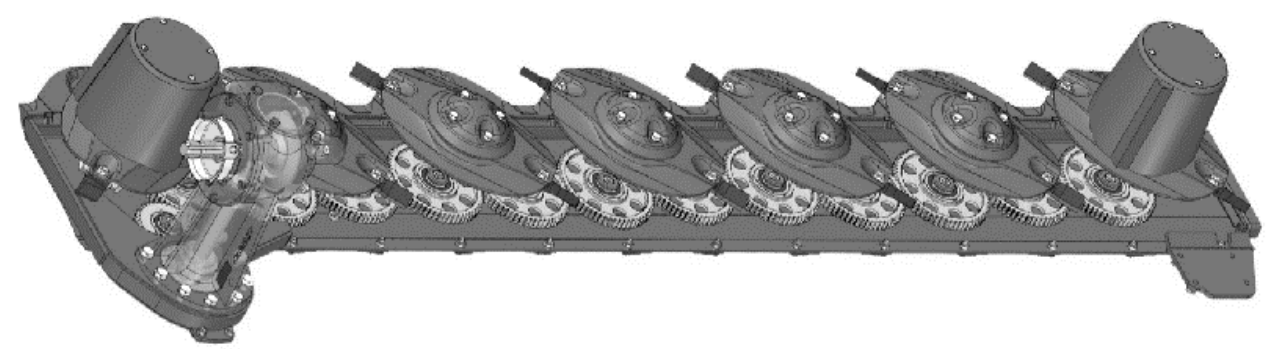

Fig. 1. Perfect CUT disc strip

This feature is designed to prevent knives from blocking during operation [4]. Initially made of material Boron 27 now made of DOMEX 500MC steel. Total weight is $1.519 \mathrm{~kg}$, \# $5 \mathrm{~mm}$ sheet.

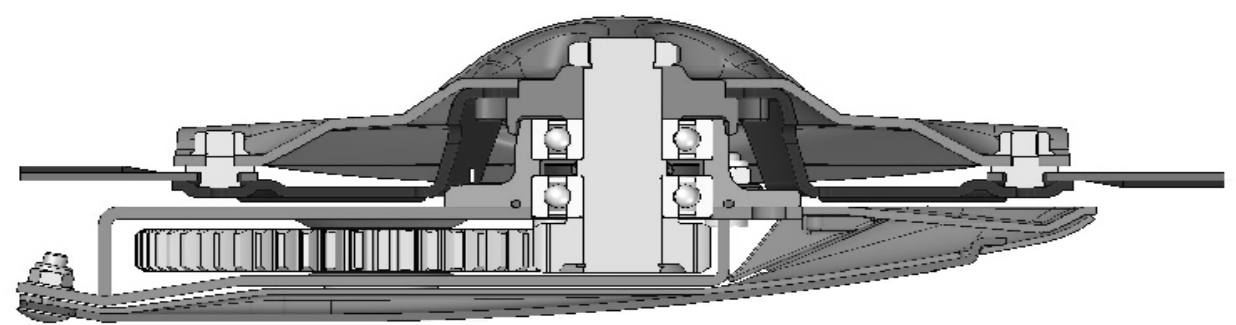

Fig. 2. Cross-section of cutting bar

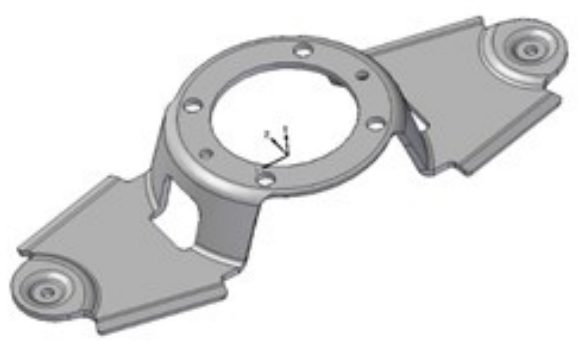

Fig. 3. Knife holder made of boron steel 


\subsection{Technological process of knife holder}

SaMASZ Disc Mower Technology Processes:

- 005 - Cutting Sheet Sheet - LASER

- 010 - Cuts the disk holder - cracks and micro-cracks occur in the process - PRESSES

- 015 - Punch the holes of the disk holder - PRESS

- 020 - Finished (2 pages) - PRESS

- 025 - Temper and temper

Afterwards, the bracelets are subjected to a hardening process and the cracks become even more visible in the process. The heat treatment process aims to improve the mechanical properties of the material by causing significant changes in their internal structure. However, during this process, the accompanying physicochemical phenomena may affect the material so that, instead of improving, it may impair the mechanical properties of the metal materials [5]. In this case, they may cause internal stresses, which will affect the strength of the object at the point of focus and cause permanent deformation and cracks. The above disadvantages associated with the hardening process lead to cracks in the structure of the material from which they are made, which results in an increase in their costs during production. Cracks in the heat-treated parts due to internal stresses create the greatest problems in the manufacturing process of finished goods [6].

\section{Analysis, identification of cracks occurring during pre- pressing, corrective actions}

At the end of 2016, during the hardness testing of parts after hardening of the quality control department, he noticed cracks and micro cracks in the holders. At the beginning of the study, two parties were analyzed.

Table 1. Summary of the test batches of knife holders

\begin{tabular}{|c|c|c|c|c|}
\hline $\begin{array}{c}\text { Lot } \\
\text { number }\end{array}$ & $\begin{array}{c}\text { Counts } \\
\text { pieces in } \\
\text { the party }\end{array}$ & Material & Defective details & $\begin{array}{c}\text { \% Of defective details in } \\
\text { relation to the tested lot }\end{array}$ \\
\hline I & 900 & $\begin{array}{c}\text { DOMEX } \\
500 \mathrm{MC}\end{array}$ & 70 & $8 \%$ \\
\hline II & 900 & $\begin{array}{c}\text { DOMEX } \\
500 \mathrm{MC}\end{array}$ & 234 & $26 \%$ \\
\hline
\end{tabular}

Then the separated holders - 304 pieces were divided into groups shown in Table 2 . 
Table 2. Types of defects created after pre-press

\begin{tabular}{|c|c|c|c|}
\hline Lp. & Kind of defect & $\begin{array}{c}\text { The number } \\
\text { of items }\end{array}$ & Dealing with defects \\
\hline 1 & Cracks are not visible & 137 & Conditionally accepted \\
\hline 2 & Cracks $\leq 3 \mathrm{~mm}$ & 21 & $\begin{array}{c}\text { Cracks were hardened after } \\
\text { quenching - allowed for production }\end{array}$ \\
\hline 3 & Cracks above $>3 \mathrm{~mm}$ & 146 & Not allowed for production \\
\hline
\end{tabular}

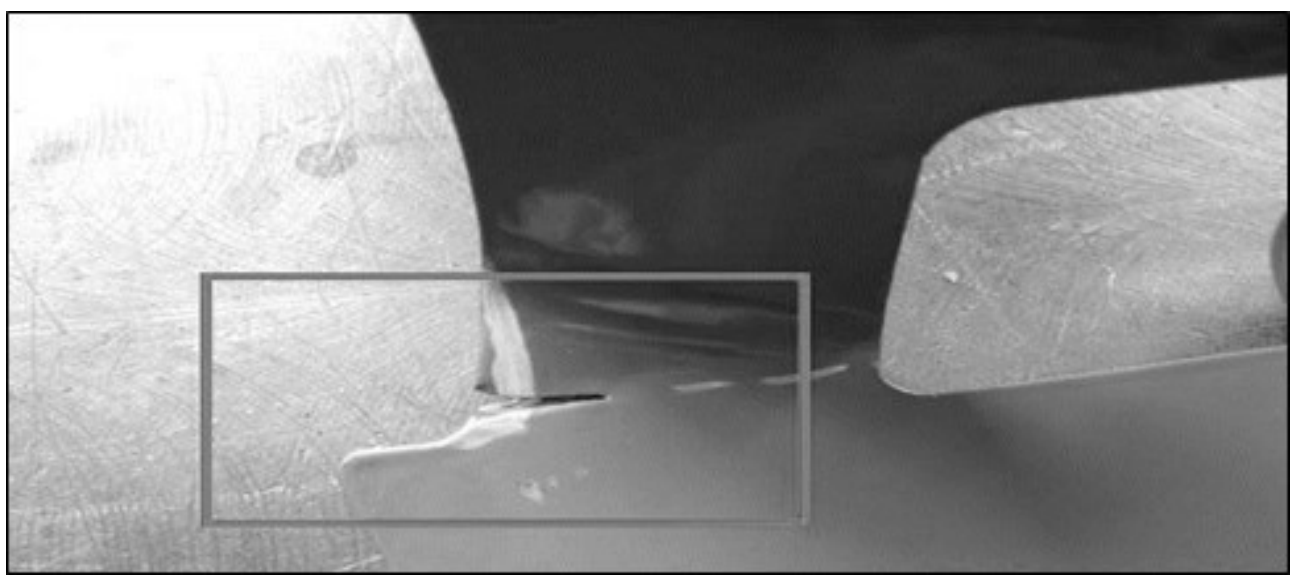

Fig. 4. Cracking occurred during the pressing process, cracking less than $3 \mathrm{~mm}$.

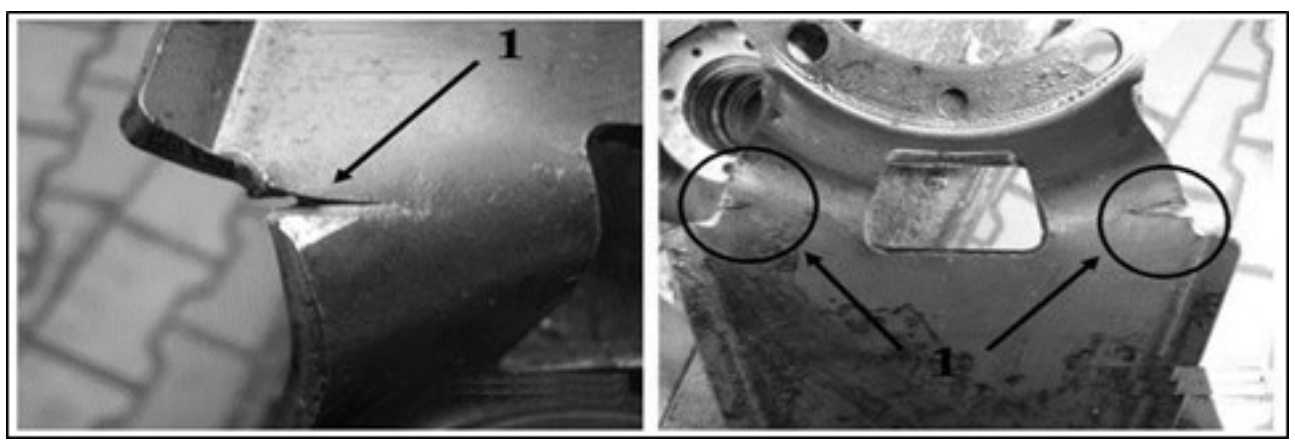

Fig. 5. Cracking occurred during the pressing process, cracking above $3 \mathrm{~mm}$. 


\subsection{Target improvements to the technology process of the holder}

SaMASZ made two changes to prevent defects in parts:

A. Construction change - the handle has been redesigned, a change in the blank of the holder has been applied by increasing the radius (figure 6). This change was strategic, because after this change, the crooks do not show cracks.

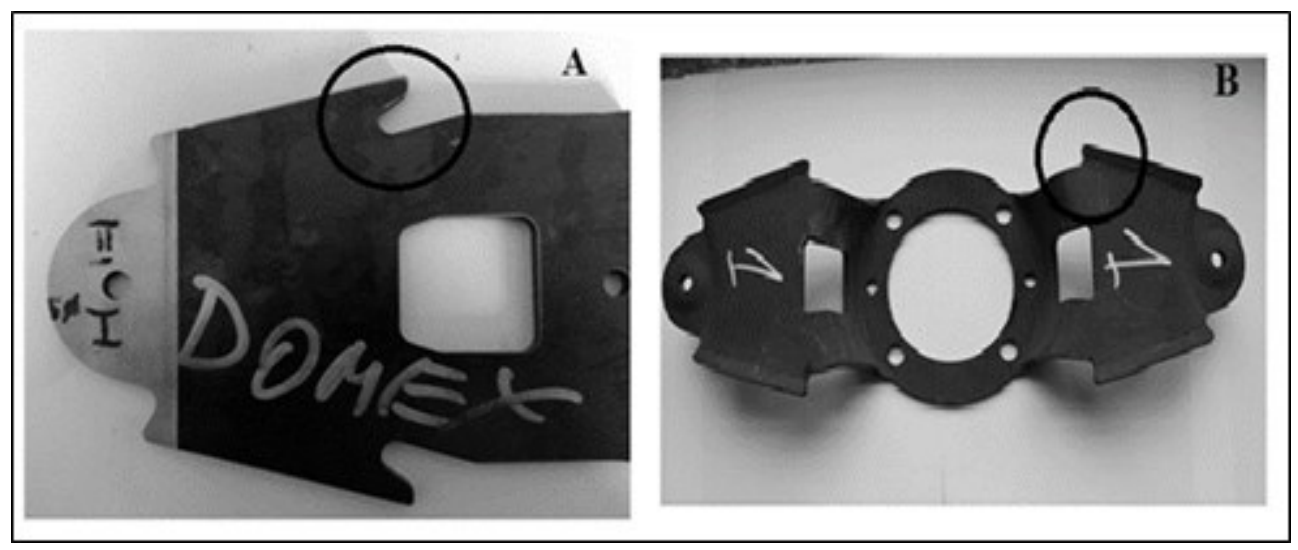

Fig. 6. A - a new type of stick holder, B - old type holder, susceptible to cracks Both of them are made of DOMEX 500 material

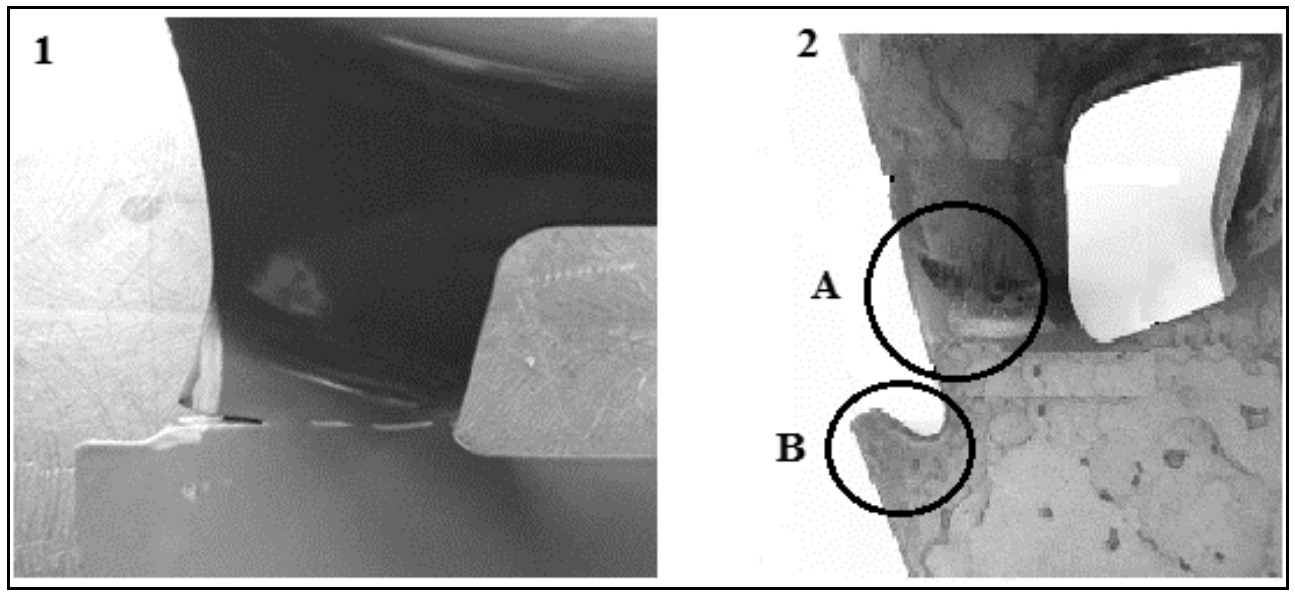

Fig. 7. 1 - old type sticker, 2 - new type sticker

A - after the structural change, there are no cracks, B - increased radius of the sting

B. Change in the organization of the technological process - the second action to avoid cracking on the products is to not postpone the crosshatch of the sheets (Figure 8) across the sheet after rolling the sheet. 


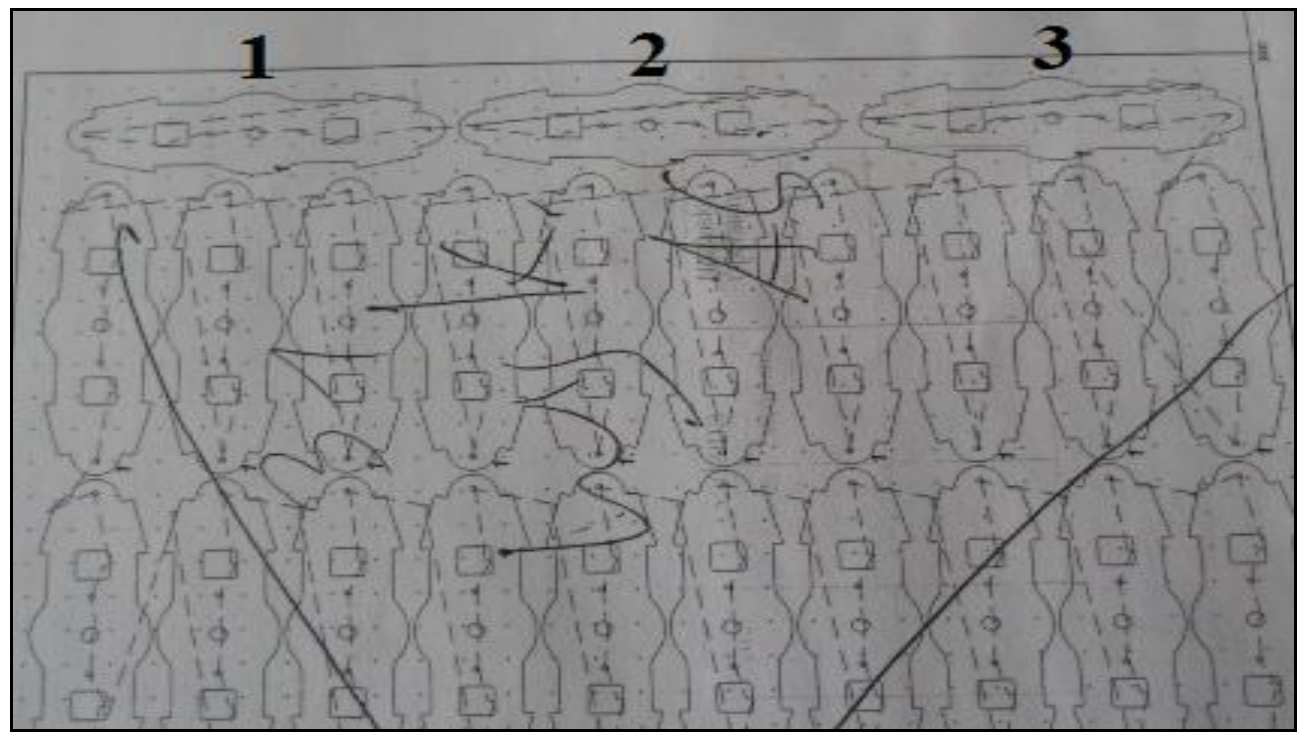

Fig. 8. Incorrect placement of parts on sheet metal - marked 1- 3

\section{Endurance tests, bending simulations of the holder during blade replacement, ultrasonic defectoscopy}

For the technological research of the holders we used 8 samples made in SAMASZ company. Hardened central knife holders with cracks after pressing, were prepared for checking resistance to cyclic bending- real work simulation using a specially shaped key. View of the station and the way of simulation is shown in Figure 9.

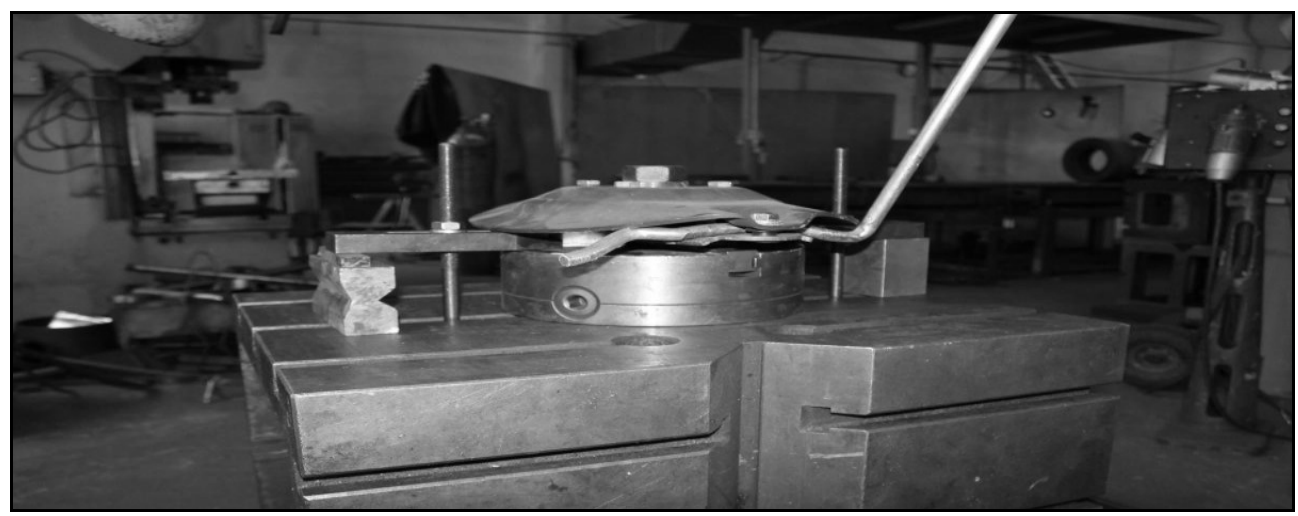

Fig. 9. The stand for research of holders resistance at the PB Institute of Innovation 
Table 3. Group I - Holders No. 1 and No. 2 - Cracks not visible to $1 \mathrm{~mm}$, not welded

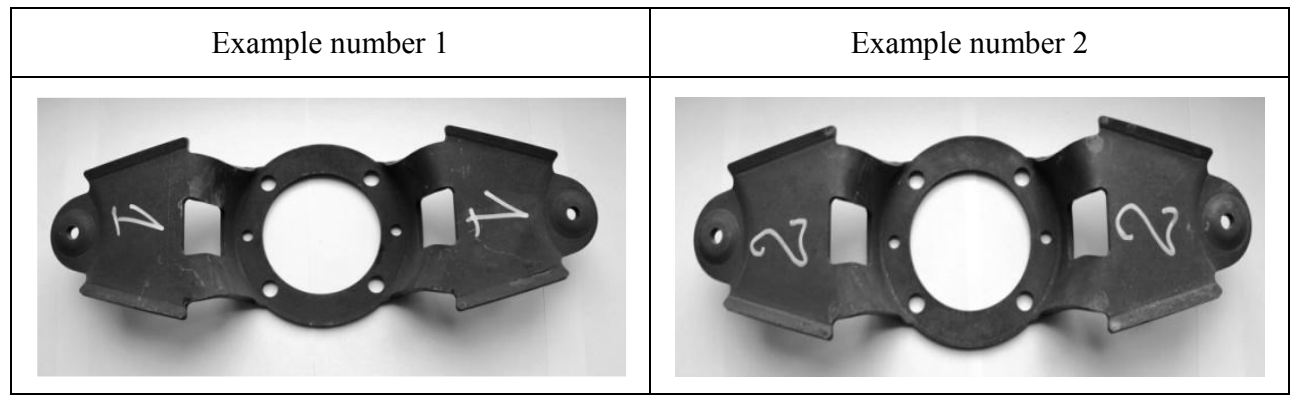

Table 4. II group - holders no 3 and no. 4 - cracks up to $3 \mathrm{~mm}$, welded and grinded

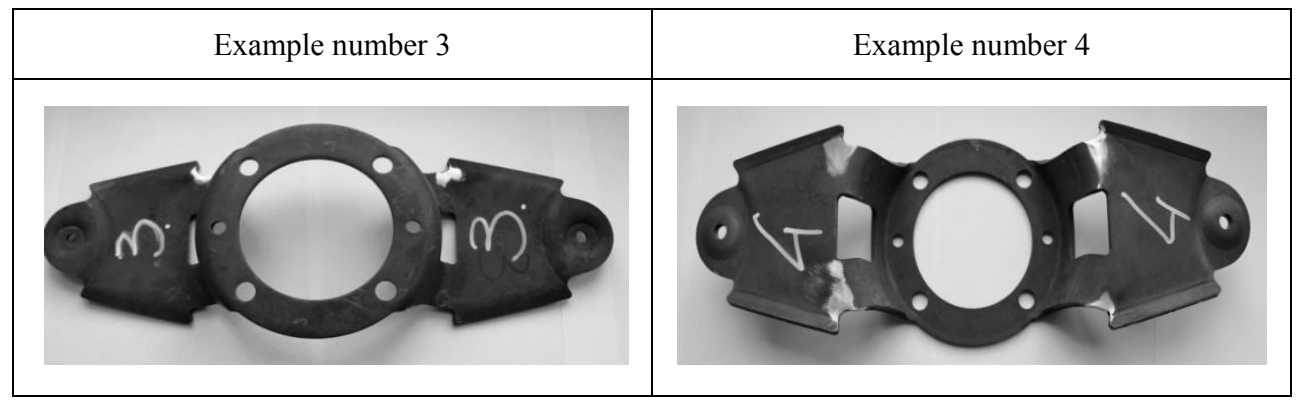

Table 5. Third group - Holders No. 5 and No. 6 - Cracks above 3 mm, welded and grinded

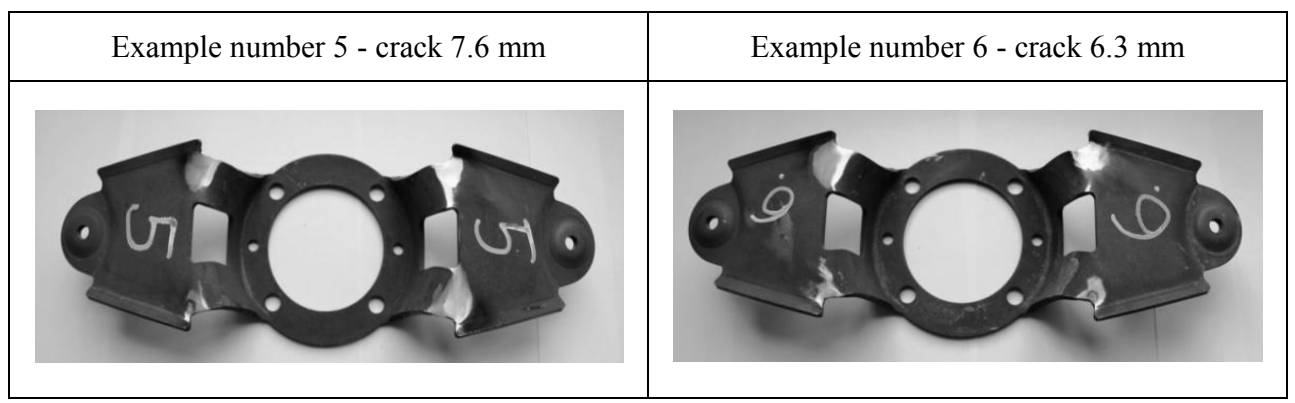

Table 6. IV group - holders No. 7 and No. 8 - no cracks

\begin{tabular}{|c|c|c|}
\hline \multicolumn{2}{|c|}{ Example number 7} & Example number 8 \\
\hline
\end{tabular}


Defected holders were regenerated by welding cracked places by MAG method. The next step was to grinding welds equally with the holder. To make sure if regenerated holders are ready to use in production, We made bending tests for holders exactly with the side of insert and remove of the holders knife.

\subsection{Description of research results}

Test conditions:

- temperature $=23{ }^{\circ} \mathrm{C}$

- Frequency $=2 \mathrm{~s}$

- $\quad$ surface condition - surface cleaned, ground

- hardness of the material (DOMEX 500HB)

Table 7. I group - holders No. 1 and No. 2 - cracks not visible to $1 \mathrm{~mm}$, not welded

\begin{tabular}{|c|c|c|}
\hline Sample number & Number of cycles & Conclusions \\
\hline I & 200 & \multirow{2}{*}{$\begin{array}{c}\text { Cracks less visible to } 1 \mathrm{~mm} \text {, as at the beginning of } \\
\text { the sample test }\end{array}$} \\
\hline II & 400 & \\
\hline III & 600 & \\
\hline
\end{tabular}

Table 8. II group - holders no 3 and no. 4 - cracks up to $3 \mathrm{~mm}$, covered and sanded

\begin{tabular}{|c|c|c|}
\hline Sample number & Number of cycles & Conclusions \\
\hline I & 200 & \multirow{2}{*}{ No visible cracks in material structure } \\
\hline II & 400 & \\
\hline III & 600 & \\
\hline
\end{tabular}

Table 9. III group - Holders No. 5 and No. 6 - Cracks above $3 \mathrm{~mm}$, covered and ground

\begin{tabular}{|c|c|c|}
\hline Sample number & Number of cycles & Conclusions \\
\hline I & 200 & \multirow{2}{*}{ No visible cracks in material structure } \\
\hline II & 400 & \\
\hline III & 600 & \\
\hline
\end{tabular}

Table 10. IV group - holders No. 7 and No. 8 - no cracks

\begin{tabular}{|c|c|c|}
\hline Sample number & Number of cycles & Conclusions \\
\hline I & 200 & \multirow{2}{*}{ No visible cracks in material structure } \\
\hline II & 400 & \\
\hline III & 600 & \\
\hline
\end{tabular}




\subsection{60 METRISON flaw detector tests}

For the reliability of the study, SaMASZ Sp. Z o. o. gave a defectoscope sample without regeneration, with cracks after pressing.

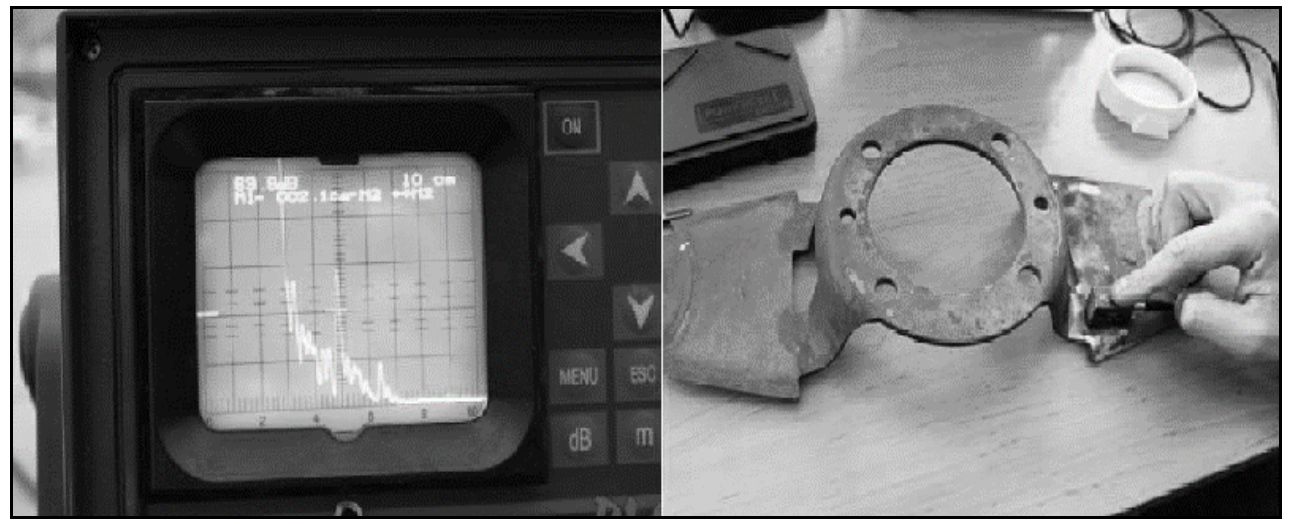

Fig. 10. Diffusion test with DI 60, holder showing cracks

In Figure 10 we see that the stick exhibits discontinuity of material. From ultrasonic flaw detection, we read a distance value of $2.1 \mathrm{~cm}$. The distance of the center of the head from its origin is $1.4 \mathrm{~cm}$, so the microcracks are $0.7 \mathrm{~cm}$ from the beginning of the head [7].

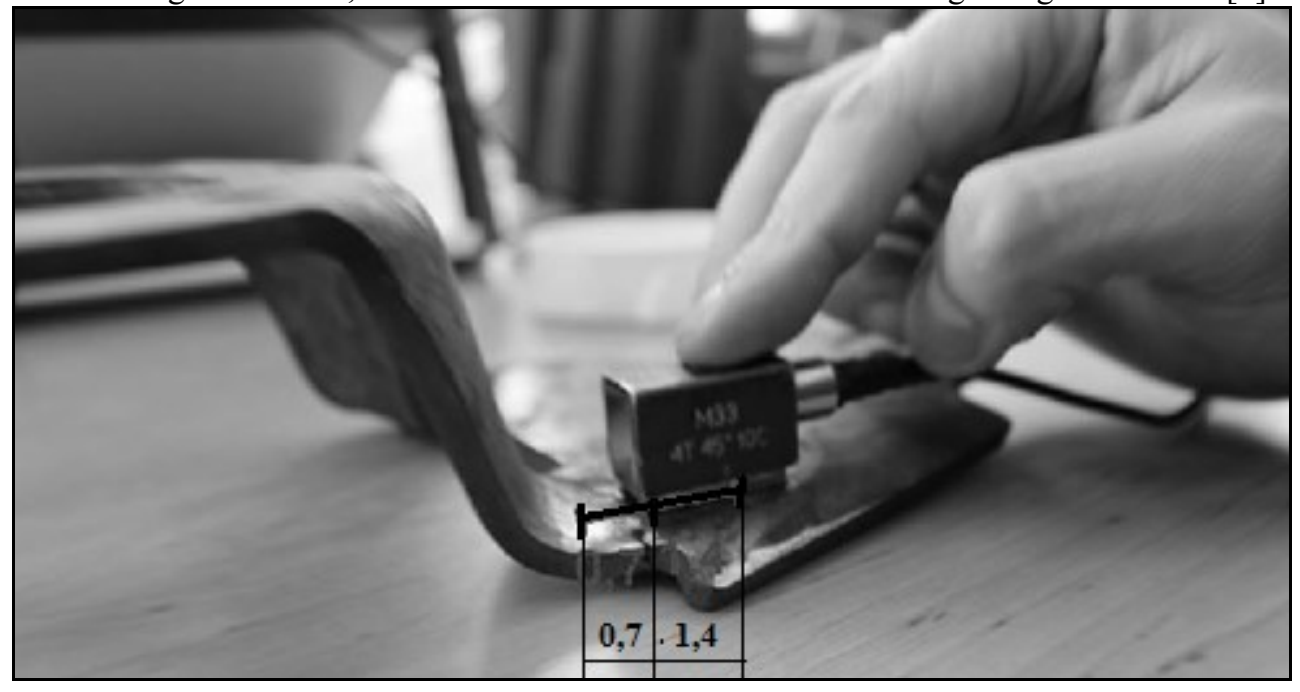

Fig. 11. Location for cracks in knife holder

Subsequently, samples subjected to knife replacement simulations were examined. Defectoscopy studies are aimed at detecting and identifying sites of discontinuity [8]. Examination of 8 samples showed no cracks and microcracks in the material structure. 


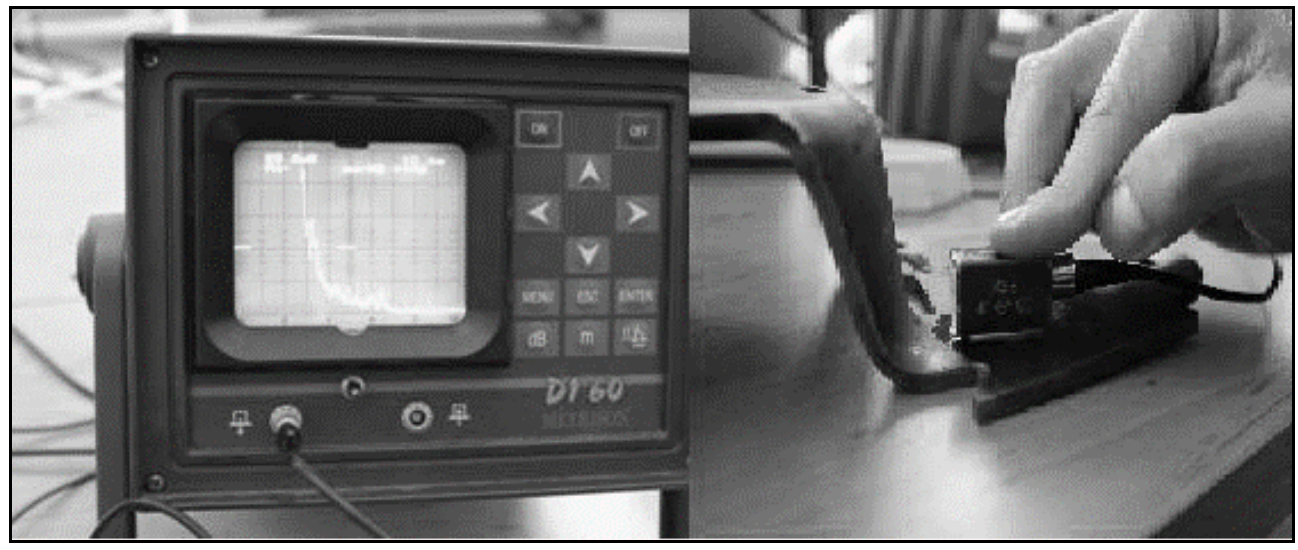

Fig. 12. Defectoscopic examination of 8 samples - no cracks

\section{Conclusions}

The analysis of endurance tests and ultrasonic flaw detection allowed us to formulate the following conclusions:

- change in the technological and organizational process used to produce the knife holder, eliminating defects in the manufacture of the work piece;

- regenerated by welding (MAG method) knife holders, can be used for further production.

So, the problem that arose from the need to convert Boron 27 steel to a new type of material (DOMEX 500MC) was resolved. Knife holders, made of new sheet metal and regenerated details, do not show any cracks, so they are safe to use.

\section{References}

1. M. Feld, Fundamentals of technological process design of typical machine parts. (Scientific and Technical Publishing House, Warsaw, 2003)

2. M. Kapcińska, K. Żurowski, M. Gościański, Analysis of new generation of materials used for selected elements in machine construction working in extremely difficult conditions of erosion and tribological wear in terms of increasing their service life. Works by PIMR, TT - 4 (2008)

3. A. Stolarski, S. Rabiczko, D. Kułak, J. Jaroszewicz, Innovative and energy-efficient manufacturing techniques in machine construction at SaMASZ Sp. Z. o. o. Energy in science and technology 2012, Publisher Bialystok Technical University, 148-156, Bialystok (2012)

4. J. Jaroszewicz, A. Stolarski, D. Kułak, Innovative technological and constructional solutions in modern machines for the greenery on the example of SaMASZ Sp. Z o.o.. Energy in science and technology 2013, Publisher Bialystok Technical University, 57-71, Bialystok (2013)

5. M. Łabęcki, M. Gościański, D. Kapcińska, Z. Pirowski, Tribological, Strength and structural investigations of selected materials used for elements of agricultural machines working in the soil. Industrial Institute of Agricultural Machinery. Poznan, 52, (2007) 
6. J. Napiórkowski, Spatial impact of soil on working elements of agricultural tools, Agricultural Engineering 17, (2005)

7. L. Filipczyński, Z. Pawłowski, Ultrasonic Materials Research. Materials for SITMP course. (Ed. INCO, Warsaw, 1962)

8. A. Śliwiński, Ultrasounds and their application. (WNT Publishing House, Warsaw, 2001) 